HETEROCYCLES, Vol. 82, No. 1, 2010, pp. 31 - 61. ๑ The Japan Institute of Heterocyclic Chemistry DOI: $10.3987 / C O M-10-S(E)$ publications

\title{
ALBERT ESCHENMOSER LIST OF SCIENTIFIC PUBLICATIONS
}

1. A. Eschenmoser, H. Schinz Zur Kenntnis der Sesquiterpene und Azulene. 91. Mitt. Zur Konstitution des Zingiberens Helv. Chim. Acta, 1950, 33, 171

2. Albert Eschenmoser Zur säurekatalysierten Zyklisierung bei Mono- und Sesquiterpenverbindungen Promotionsarbeit Nr. 2018, ETH Zürich, Juris-Verlag Zürich, 1952

3. A. Eschenmoser, A. Fürst Zur Konstitution der Caryophyllensäure Experientia, 1951, 7, 290

4. A. Eschenmoser, J. Schreiber, W. Keller Zur Kenntnis der Sesquiterpene und Azulene. 97. Mitt. Zur Konstitution des Lanceols Helv. Chim. Acta, 1951, 34, 1667

5. A. Eschenmoser, H. Schinz, R. Fischer, J. Colonge Zur Konstitution des Cycloartemisiaketons Helv. Chim. Acta, 1951, 34, 2329

6. A. Eschenmoser, Hs.H. Günthard Zur Kenntnis der Sesquiterpene und Azulene. 98. Mitt. Zur Cyclisation des $\beta-$ Caryophyllens Helv. Chim. Acta, 1951, 34, 2338

7. A. Eschenmoser, A. Frey Über die Spaltung des Mesylesters von 2-Methyl-2-oxymethyl-cyclopentanon mit Basen Helv. Chim. Acta, 1952, 35, 1660

8. A. Eschenmoser, H. H. Rennhard Über eine stufenweise Reduktion des Purpurogallin-tetramethyläthers Helv. Chim. Acta, 1953, 36, 290

9. A. Eschenmoser, J. Schreiber, S. A. Julia

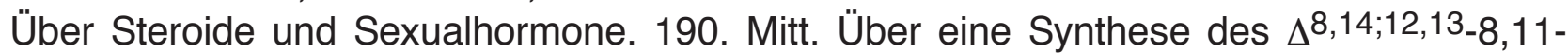
Dimethyl-1,7-dioxo-decahydro-phenanthrens Helv. Chim. Acta, 1953, 36, 482

10. E. Heilbronner, A. Eschenmoser Über das Benzo-cycloheptatrienylium-Kation Helv. Chim. Acta, 1953, 36, 1101 
11. S. A. Julia, A. Eschenmoser, H. Heusser, N. Tarköy

Zur basenkatalysierten Spaltung von 1,5-Dicarbonylverbindungen

Helv. Chim. Acta, 1953, 36, 1885

12. H. Kappeler, A. Eschenmoser, H. Schinz

Synthese und Cyclisation von 2,7-Dimethyl-octadien(2,6 bzw. 2,7)-säure-(1), eines Isomeren der Geraniumsäure mit m-Cymol-Skelett

Helv. Chim. Acta, 1953, 36, 1877

13. PI. A. Plattner, A. Fürst, A. Eschenmoser, W. Keller, H. Kläui, St. Meyer, M. Rosner Über Sesquiterpene und Azulene. 106. Mitt. Die Konstitution des Cedrens Helv. Chim. Acta, 1953, 36, 1845

14. H. Kappeler, D. Stauffacher, A. Eschenmoser, H. Schinz

Synthese und Cyclisation der 3,7-Dimethyl-octadien-(2,7)-säure-(1) und über eine neue Herstellungsart der 5-Methyl-hexen-(5)-säure-(1)

Helv. Chim. Acta, 1954, 37, 957

15. G. Gamboni, H. Schinz, A. Eschenmoser

Über den sterischen Verlauf der säurekatalysierten Cyclisation in der Terpen-reihe. Cyclisation der cis-7-Methyl-octadien-(2,6)-säure-(1)

Helv. Chim. Acta, 1954, 37, 964

16. L. Ruzicka, A. Eschenmoser, H. Heusser

Biogenesis of Steroids and Terpenic Compounds

(in: L. Ruzicka, 'The Isoprene Rule and the Biogenesis of Terpenic Compounds', Experientia, 1953, 9, 357)

Experientia, 1953, 9, 362

17. H. H. Rennhard, E. Heilbronner, A. Eschenmoser

Preparation of the Benzotropylium Cation

Chem. Ind. (London), 1955, 415

18. J. Schreiber, A. Eschenmoser

Über die relative Geschwindigkeit der Chromsäureoxydation sekundärer, alicyclischer Alkohole. Vorl. Mitt.

Helv. Chim. Acta, 1955, 38, 1529

19. W. H. Schaeppi, R. W. Schmid, E. Heilbronner, A. Eschenmoser

Untersuchungen in der Benztropylium-Reihe. I. Das 2',3',4',4-Tetramethoxybenztropylium-Kation

Helv. Chim. Acta, 1955, 38, 1874

20. A. Eschenmoser, L. Ruzicka, O. Jeger, D. Arigoni

Zur Kenntnis der Triterpene. 190. Mitt. Eine stereochemische Interpretation der biogenetischen Isoprenregel bei den Triterpenen

Helv. Chim. Acta, 1955, 38, 1890 
21. A. Melera, D. Arigoni, A. Eschenmoser, O. Jeger, L. Ruzicka

Zur Kenntnis der Triterpene. 192. Mitt. Absolute Konfiguration des Kohlen-stoffatoms 20 in $\alpha$-Amyrin, ein Beitrag zur Konstitution des Ringes $\mathrm{E}$

Helv. Chim. Acta, 1956, 39, 441

22. G. Büchi, W. S. Saar, A. Eschenmoser

The Acid Catalyzed Rearrangement of Ambreinolide

Experientia, 1956, 12, 136

23. E. Kloster-Jensen, E. Kováts, A. Eschenmoser, E. Heilbronner

Preparation of 4:5-Benzazulene

Chem. Ind. (London), 1956, R 38

24. E. Kloster-Jensen, N. Tarköy, A. Eschenmoser, E. Heilbronner

Untersuchungen in der Benztropylium-Reihe. III. 2,7-Polymethylen-4,5-benztropone

Helv. Chim. Acta, 1956, 39, 786

25. E. Kloster-Jensen, E. Kováts, A. Eschenmoser, E. Heilbronner

Zur Kenntnis der Sesquiterpene und Azulene. 117. Mitt. Über die drei isomeren Benzazulene: I. Synthese des 4,5-Benz-azulens

Helv. Chim. Acta, 1956, 39, 1051

26. H. H. Rennhard, G. Di Modica, W. Simon, E. Heilbronner, A. Eschenmoser

Untersuchungen in der Benztropylium-Reihe. VII. 2,3-Benztropon und BenztropyliumKation

Helv. Chim. Acta, 1957, 40, 957

27. P. A. Stadler, A. Nechvatal, A. J. Frey, A. Eschenmoser

Untersuchungen über den sterischen Verlauf säurekatalysierter Cyclisationen bei terpenoiden Polyenverbindungen. 1. Mitt. Cyclisation der 7,11-Dimethy1-2(trans), 6(trans), 10-dodecatrien- und der 7,11-Dimethyl-2(cis), 6(trans), 10-dodecatrien-säure (Herrn Prof.Dr. T. Reichstein zum 60. Geburtstag gewidmet)

Helv. Chim. Acta, 1957, 40, 1373

28. E. Romann, A. J. Frey, P. A. Stadler, A. Eschenmoser

Untersuchungen über den sterischen Verlauf säurekatalysierter Cyclisationen bei terpenoiden Polyenverbindungen. 2. Mitt. Dimerisation von ( \pm )-1-Methylen-5,5,8atrimethyl-trans-2-decalon (Totalsynthese von (+)-(8S,8'S)-Onoceran-8,8'-diol)

Helv. Chim. Acta, 1957, 40, 1900

29. P. A. Stadler, A. Eschenmoser, H. Schinz, G. Stork

Untersuchungen über den sterischen Verlauf säurekatalysierter Cyclisationen bei terpenoiden Polyenverbindungen. 3. Mitt. Zur Stereochemie der Bicyclofarnesylsäuren Helv. Chim. Acta, 1957, 40, 2191

30. J. Schreiber, M. Pesaro, W. Leimgruber, A. Eschenmoser Über eine neue Bildungsweise des Troponsystems. Vorl. Mitt. 
Helv. Chim. Acta, 1958, 41, 2103

31. A. Eschenmoser, D. Felix, M. Gut, J. Meier, P. Stadler Some Aspects of Acid-Catalysed Cyclizations of Terpenoid Polyenes Ciba Found. Symp. Biosynth. Terpenes Sterols, 1959, 217

32. A. G. Armour, G. Büchi, A. Eschenmoser, A. Storni Synthese und Stereochemie der isomeren Ambrinole (Herrn Dr. Max Stoll zu seinem 60. Geburtstag gewidmet) Helv. Chim. Acta, 1959, 42, 2233

33. J. Schreiber, W. Leimgruber, M. Pesaro, P. Schudel, A. Eschenmoser Synthese des Colchicins Angew. Chem., 1959, 71, 637

34. F. Elsinger, J. Schreiber, A. Eschenmoser Notiz über die Selektivität der Spaltung von Carbonsäure-methylestern mit Lithiumjodid Helv. Chim. Acta, 1960, 43, 113

35. P. A. Stadler, A. Eschenmoser, E. Sundt, M. Winter, M. Stoll Notiz über das Vorkommen isoprenoider $\mathrm{C}_{5}$-Alkohole in ätherischen Ölen Experientia, 1960, 16, 283

36. J. Schreiber, W. Leimgruber, M. Pesaro, P. Schudel, T. Threlfall, A. Eschenmoser Synthese des Colchicins Helv. Chim. Acta, 1961, 44, 540

37. C. F. Seidel, D. Felix, A. Eschenmoser, K. Biemann, E. Palluy, M. Stoll Zur Kenntnis des Rosenöls. 2. Mitt. Die Konstitution des Oxyds $\mathrm{C}_{10} \mathrm{H}_{18} \mathrm{O}$ aus bulgarischem Rosenöl Helv. Chim. Acta, 1961, 44, 598

38. J. Rocek, F. H. Westheimer, A. Eschenmoser, L. Moldoványi, J. Schreiber Chromsäureester als Zwischenprodukte bei der Oxydation von Alkoholen. Geschwindigkeits-limitierende Veresterung eines sterisch gehinderten Alkohols Helv. Chim. Acta, 1962, 45, 2554

39. H. Brechbühler, H. Büchi, E. Hatz, J. Schreiber, A. Eschenmoser Veresterung von Carbonsäuren mit Amidacetalen Angew. Chem., 1963, 75, 296

40. H. Büchi, K. Steen, A. Eschenmoser

N.N-Dimethylformamid-dineopentylacetal: ein Reagens zur Veresterung von Carbonsäuren mit Benzylalkoholen Angew. Chem., 1963, 75, 1176

41. H. Peter, M. Brugger, J. Schreiber, A. Eschenmoser 
Notiz über eine Darstellungsmethode für $N$-Methyl-aminosäuren Helv. Chim. Acta, 1963, 46, 577

42. R. Darms, T. Threlfall, M. Pesaro, A. Eschenmoser Cycloheptatrien-1,6-dicarbonsäure und Bicyclo[4,1,0]-2,4-heptadien-1,6dicarbonsäureanhydrid Helv. Chim. Acta, 1963, 46, 2893

43. A. Eschenmoser

Studies on the Synthesis of Corrins

Pure Appl. Chem., 1963, 7, 297

44. E. Bertele, H. Boos, J. D. Dunitz, F. Elsinger, A. Eschenmoser, I. Felner, H. P. Gribi, H. Gschwend, E. F. Meyer, M. Pesaro, R. Scheffold

Ein synthetischer Zugang zum Corrinsystem

(Herrn Prof. H. Meerwein zum 85. Geburtstag gewidmet)

Angew. Chem., 1964, 76, 393

A Synthetic Route to the Corrin System

Angew. Chem. Int. Ed., 1964, 3, 490

45. D. Felix, M. Stoll, A. Eschenmoser

Eine zweistufige Synthese der Irone aus "Pseudojonon"

Chimia, 1964, 18, 174

46. E. Bertele, R. Scheffold, M. Pesaro, I. Felner, A. Eschenmoser

Über Metallkomplexe des trans-1,8,8,13,13-Pentamethyl-5-cyan-corrins

Chimia, 1964, 18, 181

47. H. Gschwend, R. Scheffold, E. Bertele, M. Pesaro, A. Eschenmoser

Synthese von Metallkomplexen eines neuartigen porphinoiden Ligandsystems

(SCG Freiburg 1964)

Chimia, 1964, 18, 181

48. R. Scheffold, E. Bertele, M. Pesaro, A. Eschenmoser

Synthetische Kobalt-Corrin-Komplexe

(SCG Zürich 1964)

Chimia, 1964, 18, 405

49. A. E. Wick, D. Felix, K. Steen, A. Eschenmoser

Claisen'sche Umlagerungen bei Allyl- und Benzylalkoholen mit Hilfe von Acetalen des $N, N$-Dimethylacetamids

Helv. Chim. Acta, 1964, 47, 2425

50. D. Felix, P. Jakober, A. Eschenmoser

Alkali-induzierte Elimination von $\mathrm{HBr}$ in 5 -Brom- $\beta$-jonon-Derivaten

Chimia, 1965, 19, 538 
51. M. Pesaro, I. Felner-Caboga, A. Eschenmoser

Rac.-di-2-pyrrolidonyl-(5,5'), ein Zwischenprodukt zur Synthese von Corrinkomplexen Chimia, 1965, 19, 566

52. H. Brechbühler, H. Büchi, E. Hatz, J. Schreiber, A. Eschenmoser

Die Reaktion von Carbonsäuren mit Acetalen des N,N-Dimethylformamids: eine Veresterungsmethode

Helv. Chim. Acta, 1965, 48, 1746

53. A. Eschenmoser, R. Scheffold, E. Bertele, M. Pesaro, H. Gschwend

Synthetic corrin complexes

Proc. R. Soc. London, Ser. A, 1965, 288, 306

54. I. Felner, A. Fischli, A. Wick, M. Pesaro, D. Bormann, E.L. Winnacker, A. Eschenmoser rac.-Dicyanocobalt(III)-1,2,2,7,7,12,12-heptamethylcorrin

Angew. Chem., 1967, 79, 863

rac.-Dicyano-(1,2,2,7,7,12,12-heptamethylcorrin)-cobalt(III)

Angew. Chem. Int. Ed., 1967, 6, 864

55. A. Fischli, A. Eschenmoser

Ein synthetischer Zugang zu metallfreien Corrinen

Angew. Chem., 1967, 79, 865

A Synthetic Route to Metal-free Corrins

Angew. Chem. Int. Ed., 1967, 6, 866

56. D. Bormann, A. Fischli, R. Keese, A. Eschenmoser

Ligandreaktivität in synthetischen Cobalt(III)- und Nickel(II)-corrin-Komplexen

Angew. Chem., 1967, 79, 867

Reactivity of Ligands in Synthetic Cobalt(III)- and Nickel(II)-corrin Complexes

Angew. Chem. Int. Ed., 1967, 6, 868

57. A. Eschenmoser, D. Felix, G. Ohloff

Eine neuartige Fragmentierung cyclischer $\alpha, \beta$-ungesättigter Carbonylsysteme; Synthese von Exalton und rac-Muscon aus Cyclododecanon

Helv. Chim. Acta, 1967, 50, 708

58. T. Petrzilka, W. Haefliger, C. Sikemeier, G. Ohloff, A. Eschenmoser

Synthese und Chiralität des (-)-Cannabidiols. Vorl. Mitt.

Helv. Chim. Acta, 1967, 50, 719

59. J. Schreiber, D. Felix, A. Eschenmoser; M. Winter, F. Gautschi, K. H. Schulte-Elte, E. Sundt, G. Ohloff, J. Kalvoda, H. Kaufmann, P. Wieland, G. Anner

Die Synthese von Acetylen-carbonyl-Verbindungen durch Fragmentierung von $\alpha, \beta$-Epoxyketonen mit p-Toluolsulfonylhydrazin. Vorl. Mitt.

Helv. Chim. Acta, 1967, 50, 2101

60. P. Wieland, H. Kaufmann, A. Eschenmoser 
Fragmentierung von $\alpha, \beta$-Epoxy-ketoximen zu Acetylenketonen. Vorl. Mitt. Helv. Chim. Acta, 1967, 50, 2108

61. A. Eschenmoser

Die Synthese von Corrinen

Mod. Sviluppi Sint. Org., 10th Corso Estivo Chim. 1967

Accad. Naz. Lincei, 1968, 181

62. D. Felix, A. Eschenmoser

Langsame Inversion am pyramidal gebundenen Stickstoff: Isolierung von diastereomeren 7-Chlor-7-azabicyclo[4.1.0]heptanen bei Raumtemperatur

Angew. Chem., 1968, 80, 197

Slow Inversion at Pyramidal Nitrogen: Isolation of Diastereomeric 7-Chloro-7-azabicyclo[4.1.0]heptanes at Room Temperature

Angew. Chem. Int. Ed., 1968, 7, 224

63. A. P. Johnson, P. Wehrli, R. Fletcher, A. Eschenmoser

Corphin, ein corrinoid-porphinoides Ligandsystem

Angew. Chem., 1968, 80, 622

Corphin, a Corrinoid-Porphinoid Ligand System

Angew. Chem. Int. Ed., 1968, 7, 623

64. D. Felix, J. Schreiber, K. Piers, U. Horn, A. Eschenmoser

Eine neue Version der Epoxyketon $\varnothing$ Alkinon-Fragmentierung: Thermischer Zerfall der Hydrazone aus $\alpha, \beta$-Epoxycarbonylverbindungen und $N$-Amino-aziridinen. Vorl. Mitt.

Helv. Chim. Acta, 1968, 51, 1461

65. Y. Yamada, D. Miljkovic, P. Wehrli, B. Golding, P. Löliger, R. Keese, K. Müller, A. Eschenmoser

Ein neuer synthetischer Zugang zum Corrinsystem

Angew. Chem., 1969, 81, 301

A New Type of Corrin Synthesis

Angew. Chem. Int. Ed., 1969, 8, 343

66. D. Felix, K. Gschwend-Steen, A. E. Wick, A. Eschenmoser

Claisen'sche Umlagerungen bei Allyl- und Benzylalkoholen mit 1-Dimethylamino-1methoxy-äthen

Helv. Chim. Acta, 1969, 52, 1030

67. K. Müller, A. Eschenmoser

Langsame Inversion am pyramidal gebundenen Stickstoff: Isolierung und Epimerisierung diastereomerer N-Methoxy-3,3-di-methoxycarbonyl-5-cyan-1,2-oxazolidine. Vorl. Mitt.

Helv. Chim. Acta, 1969, 52, 1823

68. A. Eschenmoser

Current Aspects of Corrinoid Synthesis

Proc. Robert A. Welch Found. Conf. Chem. Res., 1968, 12, 9 
69. A. Eschenmoser

The Role of Transition Metals in the Chemical Synthesis of Corrins Pure Appl. Chem., 1969, 20, 1

70. P. Dubs, E. Götschi, M. Roth, A. Eschenmoser

Sulfidkontraktion via alkylative Kupplung: eine Methode zur Darstellung poten-tieller $\beta$ Dicarbonylsysteme (SCG St. Gallen 1969)

Chimia, 1970, 24, 34

71. R. K. Müller, D. Felix, J. Schreiber, A. Eschenmoser

Zur Stereochemie der thermischen Fragmentierung von Hydrazonderivaten substituierter $\mathrm{N}$-Amino-aziridine. Vorl. Mitt.

(Herrn Dr. O. Isler zum 60. Geburtstag gewidmet)

Helv. Chim. Acta, 1970, 53, 1479

72. L. Tenud, S. Farooq, J. Seibl, A. Eschenmoser

Endocyclische $\mathrm{S}_{\mathrm{N}}$-Reaktionen am gesättigten Kohlenstoff? Vorl. Mitt.

Helv. Chim. Acta, 1970, 53, 2059

73. A. Eschenmoser

Roads to Corrins (Centenary Lecture)

Quart. Rev., 1970, 24, 366

74. M. Roth, P. Dubs, E. Götschi, A. Eschenmoser

Sulfidkontraktion via alkylative Kupplung: eine Methode zur Darstellung von $\beta$-Dicarbonylderivaten. Über synthetische Methoden. 1. Mitt.

Helv. Chim. Acta, 1971, 54, 710

75. J. Schreiber, H. Maag, N. Hashimoto, A. Eschenmoser

Dimethyl-methylen-immonium-jodid. Über synthetische Methoden. 2. Mitt.

Angew. Chem., 1971, 83, 355

Dimethyl(methylene)ammonium lodide

Angew. Chem. Int. Ed., 1971, 10, 330

76. A. Eschenmoser

Studies on organic synthesis in: 23rd Int. Congress of Pure and Applied Chemistry, Vol. 2, Butterworths, London, 1971, p. 69

77. D. Felix, J. Schreiber, G. Ohloff, A. Eschenmoser

$\alpha, \beta$-Epoxyketon $\varnothing$ Alkinon-Fragmentierung I: Synthese von Exalton und rac-Muscon aus Cyclododecanon. Über synthetische Methoden. 3. Mitt.

(Herrn Dr. Roger Firmenich zum 65. Geburtstag gewidmet)

Helv. Chim. Acta, 1971, 54, 2896

78. D. Felix, R. K. Müller, U. Horn, R. Joos, J. Schreiber, A. Eschenmoser $\alpha, \beta$-Epoxyketon $\varnothing$ Alkinon-Fragmentierung II: Pyrolytischer Zerfall der Hydrazone aus $\alpha, \beta$-Epoxyketonen und N-Amino-aziridinen. Über synthetische Methoden. 4. Mitt. 
(Herrn Prof.Dr. A. Wettstein zum 65. Geburtstag gewidmet) Helv. Chim. Acta, 1972, 55, 1276

79. W. Fuhrer, P. Schneider, W. Schilling, H. Wild, J. Schreiber, A. Eschenmoser

Totalsynthese von Vitamin $\mathrm{B}_{12}$ : die photochemische Secocorrin $\varnothing$ CorrinCycloisomerisierung

H. Maag, N. Obata, A. Holmes, P. Schneider, W. Schilling, J. Schreiber, A. Eschenmoser Totalsynthese von Vitamin $B_{12}$ : Endstufen (SCG Zürich 1972)

Chimia, 1972, 26, 320

80. U. M. Kempe, T. K. Das Gupta, K. Blatt, P. Gygax, D. Felix, A. Eschenmoser

$\alpha$-Chlor-nitrone I: Darstellung und $\mathrm{Ag}^{+}$-induzierte Reaktion mit Olefinen. Über synthetische Methoden. 5. (vorl.) Mitt.

Helv. Chim. Acta, 1972, 55, 2187

81. T. K. Das Gupta, D. Felix, U. M. Kempe, A. Eschenmoser

$\alpha$-Chlor-nitrone II: Eine Methode zur Darstellung von $\gamma$-Lactonen aus Olefinen. Über synthetische Methoden. 6. (vorl.) Mitt.

Helv. Chim. Acta, 1972, 55, 2198

82. P. Gygax, T. K. Das Gupta, A. Eschenmoser

$\alpha$-Chlor-nitrone III: Ein Weg zur indirekten "carboxolytischen" Spaltung von OlefinDoppelbindungen. Über synthetische Methoden. 7. (vorl.) Mitt.

Helv. Chim. Acta, 1972, 55, 2205

83. S. Shatzmiller, M. Petrzilka, A. Rüttimann, A. Eschenmoser

Neues zur Chemie der $\alpha$-Chlor-nitrone

(SCG Luzern 1972)

Chimia, 1972, 26, 658

84. E. Götschi, W. Hunkeler, H.-J. Wild, P. Schneider, W. Fuhrer, J. Gleason, A. Eschenmoser

Variante des Sulfidkontraktionsverfahrens beim Aufbau corrinoider Systeme Angew. Chem., 1973, 85, 950

A Variation of the Sulfide Contraction Procedure for Synthesis of Corrinoid Systems Angew. Chem. Int. Ed., 1973, 12, 910

85. E. Götschi, A. Eschenmoser

Bildung eines 1-Hydroxy-corrin-Komplexes durch lichtinduzierte A/D-Secocorrin $\varnothing$ CorrinCycloisomerisierung

Angew. Chem., 1973, 85, 952

Formation of a 1-Hydroxycorrin Complex by Photochemical A/D-Secocorrin $\varnothing$ Corrin Cycloisomerization

Angew. Chem. Int. Ed., 1973, 12, 912

86. P. M. Müller, S. Farooq, B. Hardegger, W. S. Salmond, A. Eschenmoser 
Metallfreie Derivate des Corphin-Ligandsystems

Angew. Chem., 1973, 85, 954

Metal-Free Derivatives of the Corphin Ligand System

Angew. Chem. Int. Ed., 1973, 12, 914

87. M. Petrzilka, D. Felix, A. Eschenmoser

$\alpha$-Chlor-nitrone IV: Zur Stereochemie der $\gamma$-Lacton-Synthese und eine Methode zum Aufbau von $\alpha$-Methyliden- $\gamma$-lactonen aus Olefinen. Über synthetische Methoden. 8. (vorl.) Mitt.

Helv. Chim. Acta, 1973, 56, 2950

88. S. Shatzmiller, P. Gygax, D. Hall, A. Eschenmoser

$\alpha$-Chlor-nitrone V: Substitutionsreaktionen an Olefin- und Benzolderivaten. Eine Methode zur Darstellung von $\beta, \gamma$-ungesättigten und $\beta$-arylsubstituierten Aldehyden. Stereospezifische Bildung von tetra-alkylsubstituierten Olefindoppelbindungen. Über synthetische Methoden. 9. (vorl.) Mitt.

Helv. Chim. Acta, 1973, 56, 2961

89. S. Shatzmiller, A. Eschenmoser

$\alpha$-Chlor-nitrone VI: Ag+-induzierte Reaktion mit Acetylenderivaten. Eine neue Bildungsweise von $\alpha, \beta$-ungesättigten Carbonylsystemen. Über synthetische Methoden. 10. (vorl.) Mitt.

Helv. Chim. Acta, a 1973, 56, 2975

90. D. Arigoni, A. Eschenmoser

Das Laboratorium für organische Chemie

Chem. Rundschau., 1973, 26, 13

$90 \mathrm{a}$ A. Eschenmoser

Synthese von Vitamin B12

ETH Zürich, Jahresbericht 73, Studienjahr 1973/74, S. 14-17

91. A. Eschenmoser

Organische Naturstoffsynthese heute. Vitamin $\mathrm{B}_{12}$ als Beispiel

Naturwissenschaften, 1974, 61, 513

92. A. Eschenmoser

On Organic Natural Product Synthesis and Vitamin B 12 (R.A. Welch Award Address)

Proc.Robert A.Welch Found. Conf.Chem.Res., 1974, 18, 269

93. A. Pfaltz, B. Hardegger, P. M. Müller, S. Farooq, B. Kräutler, A. Eschenmoser

Synthese und reduktive Cyclisierung eines $\Delta^{18}$-Dehydro-A/D-secocorrin komplexes. Vorl. Mitt.

Helv. Chim. Acta, 1975, 58, 1444

94. A. Rüttimann, A. Wick, A. Eschenmoser

Notiz über eine regiospezifische Methode zur Herstellung von konjugierten Cyclo- 
hexadienen. Über synthetische Methoden. 11. Mitt.

Helv. Chim. Acta, 1975, 58, 1450

95. H. Falk, G. Hoornaert, H.-P. Isenring, A. Eschenmoser

Über Enolderivate der Chlorophyllreihe. Darstellung von 132,173-Cyclophäophorbidenolen. Vorl. Mitt.

Helv. Chim. Acta, 1975, 58, 2347

96. H.-P. Isenring, E. Zass, K. Smith, H. Falk, J.-L. Luisier, A. Eschenmoser

Über enolisierte Derivate der Chlorophyllreihe. 132-Desmethoxycarbonyl-173-desoxy$13^{2}, 17^{3}$-cyclochlorophyllid a-enol und eine Methode zur Einführung von Magnesium in porphinoide Ligandsysteme unter milden Bedingungen.

Helv. Chim. Acta, 1975, 58, 2357

97. B. Kräutler, A. Pfaltz, R. Nordmann, K. O. Hodgson, J. D. Dunitz, A. Eschenmoser Versuche zur Redox-Simulation der photochemischen A/D-Secocorrin $\varnothing$ CorrinCycloisomerisierung. Elektrochemische Oxydation von Nickel(II)-1-methyliden2,2,7,7,12,12-hexamethyl-15-cyan-1,19-secocorrinatperchlorat. Vorl. Mitt.

(Hans-Herloff Inhoffen zum 70.Geburtstag gewidmet)

Helv. Chim. Acta, 1976, 59, 924

98. A. Eschenmoser

Post-B $_{12}$ Problems in Corrin Synthesis (Robert Robinson Lecture)

Chem. Soc. Rev., 1976, 5, 377

99. P. Gygax, A. Eschenmoser

Notiz über Methoden zur Umwandlung von 1,2-Dicarbonsäuren in konjugiert ungesättigte Monocarbonsäuren. Über synthetische Methoden. 12. Mitt.

Helv. Chim. Acta, 1977, 60, 507

100. A. Eschenmoser, C. E. Wintner

Natural Product Synthesis and Vitamin $\mathrm{B}_{12}$

Science, 1977, 196, 1410

101. V. Rasetti, B. Kräutler, A. Pfaltz, A. Eschenmoser

(A $\varnothing \mathrm{D})$-Ringschluss eines Nickel(II)- $\Delta^{18}$-dehydro-1-methyliden-1,19-secocorrinats Angew. Chem., 1977, 89, 475

(A $\varnothing \mathrm{D})$-Cyclization of a Nickel(II) $\Delta^{18}$-Dehydro-1-methylidene-1,19-secocorrinate Angew. Chem. Int. Ed., 1977, 16, 459

102. A. Pfaltz, N. Bühler, R. Neier, K. Hirai, A. Eschenmoser

Photochemische und nicht-photochemische A/D-Secocorrin $\varnothing$ Corrin-Cyclisierungen bei 19-Carboxy- und 19-Formyl-1-methyliden-1,19-secocorrinaten. Decarboxylierbarkeit und Deformylierbarkeit von Nickel(II)-19-carboxy- bzw. 19-formyl-corrinaten. Vorl. Mitt. Helv. Chim. Acta, 1977, 60, 2653 
Organische Naturstoffsynthese und Vitamin $B_{12}$ (Dannie-Heinemann-Preis) Jahrb. Akad. Wiss. Göttingen, 1977, 29 (Vandenhoeck \& Ruprecht, Göttingen)

104. F. Heinzer, M. Soukup, A. Eschenmoser

Über 3,3,6,9,9-Pentamethyl-2,10-diazabicyclo[4.4.0]-1-decen und einige seiner Derivate. Über synthetische Methoden. 13. Mitt.

Helv. Chim. Acta, 1978, 61, 2851

105. K. L. Brown, L. Damm, J. D. Dunitz, A. Eschenmoser, R. Hobi, C. Kratky

Structural Studies of Crystalline Enamines

Helv. Chim. Acta, 1978, 61, 3108

106. E. Walter, J. Schreiber, E. Zass, A. Eschenmoser

Bakteriochlorophyll $\mathrm{a}_{\mathrm{Gg}}$ und Bakteriophäophytin ap in den photosynthetischen Reaktionszentren von Rhodospirillum rubrum G-9+

(Edgardo Giovannini zum 70. Geburtstag gewidmet)

Helv. Chim. Acta, 1979, 62, 899

107. D. Sternbach, M. Shibuya, F. Jaisli, M. Bonetti, A. Eschenmoser

Ein fragmentativer Zugang zu Makroliden: (5-E, 8-Z)-6-Methyl-5,8-undecadien-11-olid Angew. Chem., 1979, 91, 670

A Fragmentational Approach to Macrolides: (5-E, 8-Z)-6-methyl-5,8-undecadien-11-olide Angew. Chem. Int. Ed., 1979, 18, 634

108. M. Shibuya, F. Jaisli, A. Eschenmoser

Ein fragmentativer Zugang zu Makroliden: (5-E, 9-E)-6-Methyl-5,9-undecadien-11-olid Angew. Chem., 1979, 91, 672

A Fragmentational Approach to Macrolides: (5-E, 9-E)-6-methyl-5,9-undecadien-11-olide Angew. Chem. Int. Ed., 1979, 18, 636

109. F. Jaisli, D. Sternbach, M. Shibuya, A. Eschenmoser

Sterischer Verlauf der Reduktion von Ketoacetalestern mit Alkalimetallen in flüssigem Ammoniak

Angew. Chem., 1979, 91, 673

Steric Course of the Reduction of Ketoacetal Esters with Alkali Metals in Liquid Ammonia Angew. Chem. Int. Ed., 1979, 18, 637

110. F.-P. Montforts, S. Ofner, V. Rasetti, A. Eschenmoser, W.-D. Woggon, K. Jones, A. R. Battersby

Ein synthetischer Zugang zum Strukturtyp des Isobakteriochlorins

Angew. Chem., 1979, 91, 752

A Synthetic Approach to the Isobacteriochlorin Macrocycle Angew. Chem. Int. Ed., 1979, 18, 675

111. P. R. Jenkins, R. Gut, H. Wetter, A. Eschenmoser

Notiz über einen Zugang zu $\beta, \gamma$-ungesättigten Carbonsäurederivaten mit Hilfe der 
Amidacetal-Claisenumlagerung. Über synthetische Methoden. 17. Mitt.

(André Dreiding zum 60. Geburtstag gewidmet)

Helv. Chim. Acta, 1979, 62, 1922

112. A. Eschenmoser

Chemical Synthesis of Corrinoids: Current Problems and Recent Advances, in: B. Zagalak, W. Friedrich (Eds.), 'Vitamin $\mathrm{B}_{12}$ and Intrinsic Factor' (Proc. 3rd Europ.Symp., Zürich/CH), W. de Gruyter, Berlin, 1979, S. 89

113. C. Angst, M. Kajiwara, E. Zass, A. Eschenmoser

Gegenseitige Umwandlung der Chromophorsysteme des Porphyrinogens und des Isobakteriochlorins

Angew. Chem., 1980, 92, 139

Mutual Interconversion of the Chromophoric Systems of Porphyrinogen and Isobacteriochlorin

Angew. Chem. Int. Ed., 1980, 19, 140

114. J. E. Johansen, C. Angst, C. Kratky, A. Eschenmoser

$1,2,3,7,8,20$-Hexahydroporphyrin, ein sich leicht bildendes, zu Porphyrinogen isomeres Ligandsystem

Angew. Chem., 1980, 92, 141

1,2,3,7,8,20-Hexahydroporphyrin, an Easily Formed Ligand System Isomeric to Porphyrinogens

Angew. Chem. Int. Ed., 1980, 19, 141

115. P. Naab, R. Lattmann, C. Angst, A. Eschenmoser

Synthese und Umwandlungen des 5-Cyan-2,2,8,8,12,13,17,18-octamethylisobakteriochlorins

Angew. Chem., 1980, 92, 143

Synthesis and Transformations of 5-Cyano-2,2,8,8,12,13,17,18-octamethylisobacteriochlorin

Angew. Chem. Int. Ed., 1980, 19, 143

116. E. Zass, H. P. Isenring, R. Etter, A. Eschenmoser

Der Einbau von Magnesium in Liganden der Chlorophyll-Reihe mit (2,6-Di-t-butyl-4methylphenoxy)magnesiumjodid

Helv. Chim. Acta, 1980, 63, 1048

117. A. Kümin, E. Maverick, P. Seiler, N. Vanier, L. Damm, R. Hobi, J. D. Dunitz, A. Eschenmoser

Struktur eines O,N-Ketenacetals: (1RS,8SR,10SR,4(15)Z)-4-Äthyliden-5-oxa-3azatricyclo[8.4.0.03,8]tetradecan

Helv. Chim. Acta, 1980, 63, 1158

118. V. Rasetti, A. Pfaltz, C. Kratky, A. Eschenmoser

Ring contraction of hydroporphinoid to corrinoid complexes

Proc. Natl. Acad. Sci., U.S.A., 1981, 78, 16 
119. J. E. Johansen, V. Piermattie, C. Angst, E. Diener, C. Kratky, A. Eschenmoser Gegenseitige Umwandlung der Chromophorsysteme des Porphyrinogens und 2,3,7,8,12,13-Hexahydroporphyrins (Prof. Hans Herloff Inhoffen zum 75. Geburtstag gewidmet) Angew. Chem., 1981, 93, 273 Interconversion of the Chromophore Systems of Porphyrinogen and 2,3,7,8,12,13Hexahydroporphyrin Angew. Chem. Int. Ed., 1981, 20, 261

120. C. Angst, C. Kratky, A. Eschenmoser Cyclisierung eines Seco-porphyrinogens zu Nickel(II)-C,D-tetradehydrocorrinaten Angew. Chem., 1981, 93, 275 Cyclization of a Seco-porphyrinogen to Nickel(II) C,D-Tetradehydrocorrinates Angew. Chem. Int. Ed., 1981, 20, 263

121. S. Ofner, V. Rasetti, B. Zehnder, A. Eschenmoser Aufbau der Ligandsysteme des C,D-Tetradehydrocorrins und Isobakteriochlorins durch Sulfidkontraktion (Prof. George Büchi zum 60. Geburtstag gewidmet) Helv. Chim. Acta, 1981, 64, 1431

122. V. Rasetti, K. Hilpert, A. Fässler, A. Pfaltz, A. Eschenmoser Die Dihydrocorphinol $\varnothing$ Corrin-Ringkontraktion: Eine potentiell biomimetische Bildungsweise der Corrinstruktur Angew. Chem., 1981, 93, 1108

The Dihydrocorphinol $\varnothing$ Corrin Ring Contraction: A Potentially Biomimetic Mode of Formation of the Corrin Structure Angew. Chem. Int. Ed., 1981, 20, 1058

123. R. Schwesinger, R. Waditschatka, J. Rigby, R. Nordmann, W. B. Schweizer, E. Zass, A. Eschenmoser

Das Pyrrocorphin-Ligandsystem: Synthese des 2,2,7,7,12,12,17-Heptamethyl2,3,7,8,12,13-hexahydroporphyrins (Dem Andenken an Dr. Willi Leimgruber gewidmet) Helv. Chim. Acta, 1982, 65, 600

124. A. Fässler, A. Pfaltz, P. M. Müller, S. Farooq, C. Kratky, B. Kräutler, A. Eschenmoser Herstellung und Eigenschaften einiger hydrocorphinoider Nickel(II)-Komplexe Helv. Chim. Acta, 1982, 65, 812

125. A. Pfaltz, B. Jaun, A. Fässler, A. Eschenmoser, R. Jaenchen, H. H. Gilles, G. Diekert, R. K. Thauer

Zur Kenntnis des Faktors F430 aus methanogenen Bakterien: Struktur des porphinoiden Ligandsystems Helv. Chim. Acta, 1982, 65, 828 
Über organische Naturstoffsynthese: Von der Synthese des Vitamin $B_{12}$ zur Frage nach dem Ursprung der Corrinstruktur

Nova Acta Leopold. (Neue Folge), 1982, 55 (247), 5

127. R. Waditschatka, A. Eschenmoser

Chemie der Pyrrocorphine: Stereoselektivität bei der Porphyrinogen $\varnothing$ PyrrocorphinTautomerisierung

Angew. Chem., 1983, 95, 639

The Chemistry of Pyrrocorphins: Stereoselectivity in the Porphyrinogen $\varnothing$ Pyrrocorphin Tautomerization

Angew. Chem. Int. Ed., 1983, 22, 630

128. R. Waditschatka, E. Diener, A. Eschenmoser

Chemie der Pyrrocorphine: C-Methylierung von Pyrrocorphinaten an der Ligandperipherie Angew. Chem., 1983, 95, 641

The Chemistry of Pyrrocorphins: C-Methylation of Pyrrocorphinates at the Ligand Periphery

Angew. Chem. Int. Ed., 1983, 22, 631

129. N. J. Lewis, A. Pfaltz, A. Eschenmoser

Säurekatalysierte Entmetallierung von Nickel-hydrocorphin- und Cobalt-corrinkomplexen mit 1,3-Propandithiol

Angew. Chem., 1983, 95, 743

Acid-Catalyzed Demetalation of Nickel-Hydrocorphin and Cobalt-Corrin Complexes with 1,3-Propanedithiol

Angew. Chem. Int. Ed., 1983, 22, 735

130. N. J. Lewis, R. Nussberger, B. Kräutler, A. Eschenmoser

5,15-Bisnorcobester: eine unvorhergesehene Bildungsweise

Angew. Chem., 1983, 95, 744

5,15-Bisnorcobester: an Unexpected Mode of Formation

Angew. Chem. Int. Ed., 1983, 22, 736

131. K. Hilpert, C. Leumann, A. P. Davis, A. Eschenmoser

Chemistry of Pyrrocorphins: Synthesis of Isobacteriochlorins and Pyrrocorphins bearing a Methyl Group at the meso Position between Rings A and D

J. Chem. Soc., Chem. Commun., 1983, 1401

132. C. Leumann, K. Hilpert, J. Schreiber, A. Eschenmoser

Chemistry of Pyrrocorphins: C-Methylations at the Periphery of Pyrrocorphins and Related Corphinoid Ligand Systems

(In memory of Prof. Alan W. Johnson)

J. Chem. Soc., Chem. Commun., 1983, 1404

133. D. A. Livingston, A. Pfaltz, J. Schreiber, A. Eschenmoser, D. Ankel-Fuchs, J. Moll, R. Jaenchen, R. K. Thauer 
Zur Kenntnis des Faktors F430 aus methanogenen Bakterien: Struktur des proteinfreien Faktors

Helv. Chim. Acta, 1984, 67, 334

134. C. Leumann, A. Eschenmoser

Chemistry of Pyrrocorphins: Methylative Opening of the Macrocycle between Rings A and D, a Side Reaction in the Peripheral C-Methylation of a 20-Methyl-pyrrocorphinate J. Chem. Soc., Chem. Commun., 1984, 583

135. A. Fässler, A. Pfaltz, B. Kräutler, A. Eschenmoser

Chemistry of Corphinoids: Synthesis of a Nickel(II) Complex Containing the Chromophore System of Coenzyme F430

J. Chem. Soc., Chem. Commun., 1984, 1365

136. C. Kratky, A. Fässler, A. Pfaltz, B. Kräutler, B. Jaun, A. Eschenmoser

Chemistry of Corphinoids: Structural Properties of Corphinoid Nickel(II) Complexes Related to Coenzyme F430

J. Chem. Soc., Chem. Commun., 1984, 1368

137. A. Eschenmoser

Vitamin $\mathrm{B}_{12}$ und präbiotische Naturstoffchemie

Jahresbericht 1984 des Schweiz. Nationalfonds, 1985, 197

138. C. Kratky, R. Waditschatka, C. Angst, J. E. Johansen, J. C. Plaquevent, J. Schreiber, A. Eschenmoser

Die Sattelkonformation der hydroporphinoiden Nickel(II)-Komplexe: Struktur, Ursprung und stereochemische Konsequenzen

Helv. Chim. Acta, 1985, 68, 1312

139. A. Pfaltz, D. A. Livingston, B. Jaun, G. Diekert, R. K. Thauer, A. Eschenmoser

Zur Kenntnis des Faktors F430 aus methanogenen Bakterien: Über die Natur der Isolierungsartefakte von F430, ein Beitrag zur Chemie von F430 und zur konformationellen Stereochemie der Ligandperipherie von hydroporphinoiden Nickel(II)Komplexen

Helv. Chim. Acta, 1985, 68, 1338

140. U. Kämpfen, A. Eschenmoser

Porphyrin Synthesis by Ring Transplantation

(Harry Wasserman for his 65th birthday)

Tetrahedron Lett., 1985, 26, 5899

141. A. Fässler, A. Kobelt, A. Pfaltz, A. Eschenmoser, C. Bladon, A. R. Battersby, R. K. Thauer Zur Kenntnis des Faktors F430 aus methanogenen Bakterien: absolute Konfiguration (David Ginsburg zu seinem 65. Geburtstag gewidmet) Helv. Chim. Acta, 1985, 68, 2287

142. R. Waditschatka, C. Kratky, B. Jaun, J. Heinzer, A. Eschenmoser 
Chemistry of Pyrrocorphins: Structure of Nickel(II) ccccc-Octaethyl-pyrrocorphinate in the Solid State and in Solution. Observation of the Inversion Barrier between Enantiomorphically Ruffled Conformers

J. Chem. Soc., Chem. Commun., 1985, 1604

143. M. Ono, R. Lattmann, K. Inomata, C. Lehmann, T. Früh, A. Eschenmoser Monopyrrolische Vorläufer für die Synthese des Uroporphyrinogen-octanitrils Croatica Chem. Acta, 1985, 58, 627

144. H. Moser, A. Fliri, A. Steiger, G. Costello, J. Schreiber, A. Eschenmoser Poly(dipeptamidinium)-Salze: Definition und Methoden zur präparativen Herstellung Helv. Chim. Acta, 1986, 69, 1224

145. A. Eschenmoser Vladimir Prelog zum 80. Geburtstag 'Neue Zürcher Zeitung', Nr. 168, 24.7.1986

146. A. Eschenmoser Chemistry of Corphinoids Ann. N. Y. Acad.Sci., 1986, Bd. 471, p. 108

147a. A. Eschenmoser Hommage à 'Pg': Inauguration der Prelog-Vorlesung (Einführungsrede) Chimia, 1986, 40, 389

147b. H. Bethge, A. Eschenmoser Glückwunschschreiben an V. Prelog zum 80 . Geburtstag Leopoldina (R.3), 1986 (1988), 32, pp. 9-46

148. E. Vogel, G. Caravatti, P. Franck, P. Aristoff, C. Moody, A. M. Becker, D. Felix, A. Eschenmoser On the Stereochemistry of E'- and E"-Reactions Chem. Lett., 1987, 219

149. C. Leumann, T. Früh, M. Göbel, A. Eschenmoser Chemie der Pyrrocorphine: Biomimetische Regioselektivität der C-Methylierung an der Ligandperipherie von Magnesium(II)-uropyrrocorphinat(Typ I)-octanitrilen (Gerhard Quinkert zum 60. Geburtstag gewidmet)

Angew. Chem., 1987, 99, 273

Chemistry of Pyrrocorphins: Biomimetic Regioselectivity of C-Methylation at the Ligand Periphery of Magnesium(II) Uropyrrocorphinate(Type I)-octanitriles Angew. Chem. Int. Ed., 1987, 26, 261

150. G. Ksander, G. Bold, R. Lattmann, C. Lehmann, T. Früh, Y.-B. Xiang, K. Inomata, H.-P. Buser, J. Schreiber, E. Zass, A. Eschenmoser Chemie der $\alpha$-Aminonitrile. 1. Mitt. Einleitung und Wege zu Uroporphyrinogen-octanitrilen Helv. Chim. Acta, 1987, 70, 1115 
151. A. Eschenmoser

Vitamin $\mathrm{B}_{12}$ : Experimente zur Frage nach dem Ursprung seiner molekularen Struktur Angew. Chem., 1988, 100, 5

Vitamin $\mathrm{B}_{12}$ : Experiments Concerning the Origin of Its Molecular Structure Angew. Chem. Int. Ed., 1988, 27, 5

152. A. Eschenmoser

Professor Duilio Arigoni zum 60. Geburtstag

Chimia, 1988, 42, 390

153. A. Eschenmoser

Chemistry Cinquantenaire de la Fondation de l'Académie Pontificale des Sciences, Compte-rendu et Actes de la Session Plénière et des Célébrations, 1986 Pontif. Acad. Sci. Scr. Varia., 1988, 73, 253

154. U. Kämpfen, A. Eschenmoser

1,5,7-Triazabicyclo[4.4.0]dec-5-en als Reaktionsmedium: Präparativ ergiebige einstufige Herstellung von Etioporphyrin aus Protoporphyrin

Helv. Chim. Acta, 1989, 72, 185

155. A. Eschenmoser

Leopold Ruzicka: Von der Isoprenregel zur Frage nach dem Ursprung des Lebens

Rad Jugosl. akad. znan. umjet., kem., 1989, 7 [443], 21

156. V. G. Matassa, P. R. Jenkins, A. Kümin, L. Damm, J. Schreiber, D. Felix, E. Zass, A. Eschenmoser

Concerning the Stereochemistry of $\mathrm{S}_{\mathrm{E}^{\prime} \text {-Type Reactions }}$

(Dedicated to the memory of David Ginsburg)

Isr. J. Chem., 1989, 29, 321

157. A. Eschenmoser

'Paul Karrer', Einführungsrede am Paul Karrer Centennial Symposium (SCG Zürich 1989)

Chimia, 1989, 43, 153

158. A. Eschenmoser

Leopold Ruzicka - From the Isoprene Rule to the Question of Life's Origin

Chimia, 1990, 44, 1

159. S. Drenkard, J. Ferris, A. Eschenmoser

Chemie von $\alpha$-Aminonitrilen. Aziridin-2-carbonitril: photochemische Bildung aus 2Aminopropennitril (Otto Isler gewidmet)

Helv. Chim. Acta, 1990, 73, 1373

160. E. Wagner, Y.-B. Xiang, K. Baumann, J. Gück, A. Eschenmoser

Chemie von $\alpha$-Aminonitrilen. Aziridin-2-carbonitril, ein Vorläufer von rac- $\mathrm{O}^{3}$. Phosphoserinnitril und Glykolaldehyd-phosphat

Helv. Chim. Acta, 1990, 73, 1391 
161. D. Müller, S. Pitsch, A. Kittaka, E. Wagner, C. E. Wintner, A. Eschenmoser

Chemie von $\alpha$-Aminonitrilen. Aldomerisierung von Glykolaldehyd-phosphat zu racemischen Hexose-2,4,6-triphosphaten und (in Gegenwart von Formaldehyd) racemischen Pentose-2,4-diphosphaten: rac-Allose-2,4,6-triphosphat und rac-Ribose-2,4diphosphat sind die Reaktionshauptprodukte

Helv. Chim. Acta, 1990, 73, 1410

162. A. Eschenmoser

Kon-Tiki-Experimente zur Frage nach dem Ursprung von Biomolekülen,in: W. Gerok et al. (Eds.), 'Materie und Prozesse vom Elementaren zum Komplexen', Verh. Ges. Dtsch. Naturforsch. Ärzte (116. Versammlung, Berlin 1990), Wissenschaftl. Verlagsges. mbH., Stuttgart, 1991, S. 135-172

163. P. Venugopalan, K. Venkatesan, J. Klausen, E. Novotny-Bregger, C. Leumann, A. Eschenmoser, J. D. Dunitz

On the Methyl-Transfer Reaction in Crystalline Methyl 2-(Methylthio)benzenesulfonate: a Thermally Induced Non-Topochemical Solid-State Reaction

Helv. Chim. Acta, 1991, 74, 662

164. G. Färber, W. Keller, C. Kratky, B. Jaun, A. Pfaltz, C. Spinner, A. Kobelt, A. Eschenmoser Coenzyme F430 from Methanogenic Bacteria: Complete Assignment of Configuration Based on an X-Ray Analysis of 12,13-Diepi-F430 Pentamethyl Ester and on NMR Spectroscopy

Helv. Chim. Acta, 1991, 74, 697

165. A. Eschenmoser

Warum Pentose- und nicht Hexose-Nucleinsäuren?

Nachr. Chem. Tech. Lab., 1991, 39, 795

166. A. Eschenmoser

Zum siebzigsten Geburtstag von Dr. Jakob Schreiber

Chimia, 1991, 45, 397

167. A. Eschenmoser, M. Dobler

Warum Pentose- und nicht Hexose-Nucleinsäuren? Teil I. Einleitung und Problemstellung, Konformationsanalyse für Oligonucleotid-Ketten aus 2',3'-DideoxyglucopyranosylBausteinen ('Homo-DNS') sowie Betrachtungen zur Konformation von A- und B-DNS (G. Quinkert zum 65. Geburtstag gewidmet)

Helv. Chim. Acta, 1992, 75, 218

168. A. Eschenmoser

Chemie potentiell präbiologischer Naturstoffe

Nova acta Leopoldina NF 67, 1992 (Nr. 281), 201

169. A. Eschenmoser, E. Loewenthal

Chemistry of Potentially Prebiological Natural Products

Chem. Soc. Rev., 1992, 21, 1 
170. M. Böhringer, H.-J. Roth, J. Hunziker, M. Göbel, R. Krishnan, A. Giger, B. Schweizer, J. Schreiber, C. Leumann, A. Eschenmoser

Warum Pentose- und nicht Hexose-Nucleinsäuren? Teil II. Oligonucleotide aus 2',3'Dideoxy- $\beta$-D-glucopyranosyl-Bausteinen ('Homo-DNS'): Herstellung

Helv. Chim. Acta, 1992, 75, 1416

171. J. Hunziker, H.-J. Roth, M. Böhringer, A. Giger, U. Diederichsen, M. Göbel, R. Krishnan, B. Jaun, C. Leumann, A. Eschenmoser

Warum Pentose- und nicht Hexose-Nucleinsäuren? Teil III. Oligo(2',3'-dideoxy- $\beta$-Dglucopyranosyl)nucleotide ('Homo-DNS'): Paarungseigenschaften (In Erinnerung an Jakob Schreiber)

Helv. Chim. Acta, 1993, 76, 259

172. A. Eschenmoser

(Über) Organische Chemie (NSCG Zürich, 1993)

Chimia, 1993, 47, 148

173. A. Eschenmoser

Hexose nucleic acids

Pure Appl. Chem., 1993, 65, 1179

174. S. Pitsch, S. Wendeborn, B. Jaun, A. Eschenmoser

Why Pentose- and Not Hexose-Nucleic Acids? Part VII. Pyranosyl-RNA ('p-RNA') (Prelim. Comm.) (In memoriam Jakob Schreiber)

Helv. Chim. Acta, 1993, 76, 2161

175. G. Otting, M. Billeter, K. Wüthrich, H.-J. Roth, C. Leumann, A. Eschenmoser

Warum Pentose- und nicht Hexose-Nucleinsäuren? Teil IV. 'Homo-DNS': ${ }^{1} \mathrm{H}-,{ }^{13} \mathrm{C}-,{ }^{31} \mathrm{P}-$ und ${ }^{15} \mathrm{~N}-\mathrm{NMR}$-spektroskopische Untersuchung von ddGlc (A-A-A-A-A-T-T-T-T-T) in wässriger Lösung (Duilio Arigoni zu seinem 65. Geburtstag gewidmet)

Helv. Chim. Acta, 1993, 76, 2701

176. A. Eschenmoser

Toward a Chemical Etiology of the Natural Nucleic Acids' Structure

Proc. Robert A. Welch Found. Conf. Chem. Res., XXXVII. '40 Years of DNA

Double Helix', Houston, Texas, 1993, pp. 201-235

177. A. Eschenmoser

Towards a chemical etiology of the structure of nucleic acids

Chemistry \& Biology, April 1994, Introductory issue, iv

178. A. Eschenmoser

$\mathrm{B}_{12}$ : reminiscences and afterthoughts Ciba Foundation Symposium 180: 'The biosynthesis of the tetrapyrrole pigments', J. Wiley \& Sons, Chichester, 1994, pp. 309-332

179. A. Eschenmoser

Chemistry of Potentially Prebiological Natural Products 
Origins Life Evol. Biosphere, 1994, 24, 389

180. A. Eschenmoser

p-RNA

Ber. Bunsenges. Phys. Chem., 1994, 98, 1111

181. S.Pitsch, A. Eschenmoser

Reaction of Methoxyoxirane with Inorganic Phosphate and Reflections on SN2-Reactivity Pol. J. Chem., 1994, 68, 2383

182. A. Eschenmoser

Hundert Jahre Schlüssel-Schloss-Prinzip

Angew. Chem., 1994, 106, 2455

One Hundred Years Lock-and-Key Principle

Angew. Chem. Int. Ed., 1994, 33, 2363

183. Y.-B. Xiang, S. Drenkard, K. Baumann, D. Hickey, A. Eschenmoser

Chemie von $\alpha$-Aminonitrilen. 12. Mitt. Sondierungen über thermische Umwandlungen von $\alpha$-Aminonitrilen

Helv. Chim. Acta, 1994, 77, 2209

184. S. Pitsch, E. Pombo-Villar, A. Eschenmoser

Chemie von $\alpha$-Aminonitrilen. 13. Mitt. Über die Bildung von 2-Oxoethyl-phosphaten ('Glycolaldehyd-phosphaten') aus rac-Oxirancarbonitril und anorganischem Phosphat und über (formale) konstitutionelle Zusammenhänge zwischen 2-Oxoethyl-phosphaten und Oligo(hexo- und pentopyranosyl)nucleotid-Rückgraten

Helv. Chim. Acta, 1994, 77, 2251

185. S. Pitsch, A. Eschenmoser, B. Gedulin, S. Hui, G. Arrhenius

Mineral Induced Formation of Sugar Phosphates

Origins Life Evol. Biosphere, 1995, 25, 297

186. S. Pitsch, R. Krishnamurthy, M. Bolli, S. Wendeborn, A. Holzner, M. Minton, C. Lesueur, I. Schlönvogt, B. Jaun, A. Eschenmoser

Pyranosyl-RNA ('p-RNA'): Base-Pairing Selectivity and Potential to Replicate (Prelim. Comm.) (In memoriam Rolf Scheffold)

Helv. Chim. Acta, 1995, 78, 1621

187. J. E. Dickens, W. M. Irvine, M. Ohishi, G. Arrhenius, S. Pitsch, A. Bauder, F. Müller, A. Eschenmoser

A Search for Interstellar Oxiranecarbonitrile $\left(\mathrm{C}_{3} \mathrm{H}_{3} \mathrm{NO}\right)$

Origins Life Evol. Biosphere, 1996, 26, 97

188. A. Eschenmoser

Towards a Chemical Etiology of the Natural Nucleic Acids' Structure, in: C. Chatgilialoglu, V. Snieckus (Eds.), 'Chemical Synthesis: Gnosis to Prognosis' (Ravello/l, May 1994), NATO ASI Ser., Ser. E 320, Kluwer Academic Publ., Dordrecht, 1996, pp. 293-340 
189. P. Lohse, B. Oberhauser, B. Oberhauser-Hofbauer, G. Baschang, A. Eschenmoser Chemie von $\alpha$-Aminonitrilen. XVII. Oligo(nukleodipeptamidinium)-Salze (Vlado Prelog zu seinem 90. Geburtstag gewidmet)

Croatica Chem. Acta, 1996, 69, 535

190. R. Krishnamurthy, S. Pitsch, M. Minton, C. Miculka, N. Windhab, A. Eschenmoser

Pyranosyl-RNA: Paarung zwischen homochiralen Oligonucleotidsträngen entgegengesetzten Chiralitätssinns

Angew. Chem., 1996, 108, 1619

Pyranosyl-RNA: Base Pairing between Homochiral Oligonucleotide Strands of Opposite Sense of Chirality

Angew. Chem. Int. Ed., 1996, 35, 1537

191. A. Eschenmoser

Zur Frage nach dem Ursprung des Lebens, in: Redaktionskommission der NGZ (Hrsg.), 'Mensch und Natur' (Festschrift zur 250-Jahr-Feier der Naturforschen- den Gesellschaft in Zürich 1746-1996), Koprint AG, Alpnach Dorf, 1996, S. 62

192. A. Eschenmoser, M. V. Kisakürek

Chemistry and the Origin of Life

(Dedicated to Vlado Prelog on the occasion of his 90th birthday)

Helv. Chim. Acta, 1996, 79, 1249

193. I. Schlönvogt, S. Pitsch, C. Lesueur, A. Eschenmoser, B. Jaun, R. M. Wolf

Pyranosyl-RNA ('p-RNA'): NMR and Molecular-Dynamics Study of the Duplex Formed by Self-pairing of Ribopyranosyl-(C-G-A-A-T-T-C-G)

Helv. Chim. Acta, 1996, 79, 2316

194. R. Micura, M. Bolli, N. Windhab, A. Eschenmoser

Auch Pyranosyl-RNA bildet Haarnadel-Strukturen

(Prof. Gerhard Quinkert zum 70. Geburtstag gewidmet)

Angew. Chem., 1997, 109, 899

Pyranosyl-RNA Also Forms Hairpin Structures

Angew. Chem. Int. Ed., 1997, 36, 870-873

195. M. Bolli, R. Micura, A. Eschenmoser

Pyranosyl-RNA: chiroselective self-assembly of base sequences by ligative oligomerization of tetranucleotide-2',3'-cyclophosphates (with a commentary concerning the origin of biomolecular homochirality)

Chemistry \& Biology, 1997, 4, 309

196. C. Lehmann, B. Schweizer, C. Leumann, A. Eschenmoser

Chemie von $\alpha$-Aminonitrilen. 22. Mitt. Regioselektive Synthese und Kristallstruktur von Uroporphyrinogen-(Typ I)-octanitril

(Oskar Jeger zum 80. Geburtstag gewidmet)

Helv. Chim. Acta, 1997, 80, 1421 
197. M. Bolli, R. Micura, S. Pitsch, A. Eschenmoser

Pyranosyl-RNA: Further Observations on Replication

(Dedicated to Dieter Seebach on the occasion of his 60th birthday)

Helv. Chim. Acta, 1997, 80, 1901

198. A. Eschenmoser

Towards a Chemical Etiology of Nucleic Acid Structure

Origins Life Evol. Biosphere, 1997, 27, 535

199. A. Eschenmoser

Thoughts and Experiments on a Chemical Etiology of Nucleic Acid Structure, in: W. Fleischhacker, T. Schönfeld (Eds.), 'Pioneering Ideas for the Physical and Chemical Sciences: Josef Loschmidt's Contributions and Modern Developments in Structural Organic Chemistry, Atomistics, and Statistical Mechanics' (Loschmidt Symposium, Vienna/A, June 1995), Plenum Press, New York, 1997, pp. 41-64

200. A. Eschenmoser

Gedenkworte für Alexander Lord Todd (2.10.1907-10.1.1997) in: 'Reden und Gedenkworte', Orden pour le mérite für Wissenschaften und Künste, Lambert Schneider, Gerlingen, 1997, Bd. 27, S. 31-37

201. A. Eschenmoser

Ein 'Dorfältester' in der Welt der Chemie. Vladimir Prelog zum Gedenken 'Neue Zürcher Zeitung', Nr. 19, 24./25.1.1998

202. A. Eschenmoser

Foreword, in: B. Kräutler, D. Arigoni, B.T. Golding (Eds.), 'Vitamin B 12 and B 12 -Proteins' (4th European Symposium on 'Vitamin $B_{12}$ and $B_{12}$-Proteins', Innsbruck/A, Sept. 1996), Wiley-VCH Verlag GmbH, Weinheim, 1998, pp. V-VI

203. K. Groebke, J. Hunziker, W. Fraser, L. Peng, U. Diederichsen, K. Zimmermann, A. Holzner, C. Leumann, A. Eschenmoser

Warum Pentose- und nicht Hexose-Nucleinsäuren? Teil V. (Purin-Purin)-Basenpaarung in der homo-DNS-Reihe: Guanin, Isoguanin, 2,6-Diaminopurin und Xanthin (In Memoriam Vlado Prelog)

Helv. Chim. Acta, 1998, 81, 375

204. A. Eschenmoser

Vladimir Prelog zum Gedenken

Chimia, 1998, 52, 74

205. R. Micura, R. Kudick, S. Pitsch, A. Eschenmoser

Die gegensätzliche Orientierung der Rückgratneigung in Pyranosyl-RNA und homo-DNA korreliert mit einer entsprechend gegensätzlichen Orientierung von Duplexeigenschaften Angew. Chem., 1999, 111, 715

Opposite Orientation of Backbone Inclination in Pyranosyl-RNA and Homo-DNA Correlates with Opposite Directionality of Duplex Properties 
Angew. Chem. Int. Ed., 1999, 38, 680

206. M. Beier, F. Reck, T. Wagner, R. Krishnamurthy, A. Eschenmoser

Chemical Etiology of Nucleic Acid Structure: Comparing Pentopyranosyl- $\left(2^{\prime} \rightarrow 4^{\prime}\right)$ Oligonucleotides with RNA

Science, 1999, 283, 699

207. A. Eschenmoser

In memoriam Vlado Prelog

Chimia, 1999, 53, 126

208. A. Eschenmoser

Chemical Etiology of Nucleic Acid Structure

Science, 1999, 284, 2118

209. R. Krishnamurthy, G. Arrhenius, A. Eschenmoser

Formation of Glycolaldehyde Phosphate from Glycolaldehyde in Aqueous Solution

Origins Life Evol. Biosphere., 1999, 29, 333

210. O. Jungmann, H. Wippo, M. Stanek, H. K. Huynh, R. Krishnamurthy, A. Eschenmoser

Promiscuous Watson-Crick Cross-Pairing within the Family of Pentopyranosyl (4' $\left.\varnothing 2^{\prime}\right)$ Oligonucleotides

Org. Lett., 1999, 1, 1527

211. F. Reck, H. Wippo, R. Kudick, M. Bolli, G. Ceulemans, R. Krishnamurthy, A. Eschenmoser

L- $\alpha$-Lyxopyranosyl (4' $\left.\varnothing 3^{\prime}\right)$ Oligonucleotides: A Base-Pairing System Containing a Shortened Backbone

Org. Lett., 1999, 1, 1531

212. R. Krishnamurthy, S. Guntha, A. Eschenmoser

Regioselektive $\alpha$-Phosphorylierung von Aldosen in wässriger Lösung

Angew. Chem., 2000, 112, 2369

Regioselective $\alpha$-Phosphorylation of Aldoses in Aqueous Solution

Angew. Chem. Int. Ed., 2000, 39, 2281

213. G. Karig, A. Fuchs, A. Büsing, T. Brandstetter, S. Scherer, J. W. Bats, A. Eschenmoser, G. Quinkert

$\delta$-Peptide Analogues of Pyranosyl-RNA. Part 1. Nucleo- $\delta$-peptides Derived from Conformationally Constrained Nucleo- $\delta$-amino Acids: Preparation of Monomers Helv. Chim. Acta, 2000, 83, 1049

214. H. Schwalbe, J. Wermuth, C. Richter, S. Szalma, A. Eschenmoser, G. Quinkert $\delta$-Peptide Analogues of Pyranosyl-RNA. Part 2. Nucleo- $\delta$-peptides Derived from Conformationally Constrained Nucleo- $\delta$-amino Acids: NMR Study of the Duplex Formed by Self-pairing of the (1'S,2'S,4'S)-(phba)-Nucleo)- $\delta$-peptide-(AATAT)

Helv. Chim. Acta, 2000, 83, 1079 
215. A. Eschenmoser, R. Krishnamurthy

Chemical etiology of nucleic acid structure

Pure Appl. Chem., 2000, 72, 343

216. K.-U. Schöning, P. Scholz, S. Guntha, X. Wu, R. Krishnamurthy, A. Eschenmoser

Chemical Etiology of Nucleic Acid Structure: The $\alpha$-Threofuranosyl-(3' $\left.\rightarrow 2^{\prime}\right)$

Oligonucleotide System

Science, 2000, 290, 1347

217. A. Eschenmoser

Chemische Aetiologie des Strukturtyps der natürlichen Nukleinsäuren (Kurt-MothesGedenkvorlesung)

Jahrb. 1999 Dtsch. Akad. Naturforsch. Leopoldina (R.3), 2000, 45, 195

218. D. Arigoni, J. D. Dunitz, A. Eschenmoser

Vladimir Prelog, 23 July 1906 - 7 January 1998

Biog. Mems. Fell. R. Soc. Lond., 2000, 46, 443

219. A. Eschenmoser

Vladimir Prelog (Commemoration of Academicians) in: 'Changing Concepts of Nature at the Turn of the Millennium"

Pontif. Acad. Sci. Scri. Varia., 2000, 95, xxxv

220. A. Eschenmoser

Commencement Day (Comentario)

Rev. Soc. Quim. Méx., 2001, 45, 33 (Revista de la Sociedad Quimica de México)

221. A. Eschenmoser

RBW, Vitamin $\mathrm{B}_{12}$, and the Harvard-ETH Collaboration in: O.T. Benfey \& P. J. T. Morris (Eds.), 'Robert Burns Woodward - Architect and Artist in the World of Molecules', Chemical Heritage Foundation, Philadelphia, 2001, pp. 23-38

222. F. Reck, H. Wippo, R. Kudick, R. Krishnamurthy, A. Eschenmoser

Pentopyranosyl Oligonucleotide Systems. Part 10. The $\alpha$-L-Lyxopyranosyl-(4'Ø2')oligonucleotide System

(Edgar Heilbronner zum 80. Geburtstag gewidmet)

Helv. Chim. Acta, 2001, 84, 1778

223. A. Eschenmoser

Prologue: The Gold-Mine Parable, in: G. Quinkert, M. V. Kisakürek (Eds.), 'Essays in Contemporary Chemistry - From Molecular Structure towards Biology', Verlag Helvetica Chimica Acta, Zürich, 2001, pp. 1-6

224. A. Eschenmoser

Epilogue: Synthesis of Coenzyme B12: A Vehicle for the Teaching of Organic Synthesis, in: G. Quinkert, M. V. Kisakürek (Eds.), 'Essays in Contemporary Chemistry - From Molecular Structure towards Biology', Verlag Helvetica Chimica Acta, Zürich, 2001, pp. 
$391-441$

225. A. Eschenmoser

Design versus Selection in Chemistry and Beyond, in: 'Science and the Future of Mankind - Science for Man and Man for Science'

Pontif. Acad. Sci. Scri. Varia., 2001, 99, 235

226. H. Wippo, F. Reck, R. Kudick, M. Ramaseshan, G. Ceulemans, M. Bolli, R. Krishnamurthy, A. Eschenmoser

Pentopyranosyl Oligonucleotide Systems. Part 11. Systems with Shortened Backbones: (D)- $\beta$-Ribopyranosyl-(4' $\left.\varnothing 3^{\prime}\right)$ - and (L)- $\alpha$-Lyxopyranosyl-(4' $\left.\varnothing 3^{\prime}\right)$-oligonucleotides (special issue honoring Professor Peter Dervan) Bioorg. Med. Chem., 2001, 9, 2411

227. P. Wentworth Jr., L. H. Jones, A. D. Wentworth, X. Zhu, N. A. Larsen, I. A. Wilson, X. Xu, W. A. Goddard, III, K. D. Janda, A. Eschenmoser, R. A. Lerner Antibody Catalysis of the Oxidation of Water Science, 2001, 293, 1806

228. A. Eschenmoser

Discours 26.11.2001 (Grande Médaille d'Or) Académie des Sciences de I'Institut de France, Extraits 2001, Tome IV, pp. 65-67

229. T. Wagner, H. K. Huynh, R. Krishnamurthy, A. Eschenmoser

Pentopyranosyl Oligonucleotide Systems. 12th comm. The $\beta$-D-Xylopyranosyl-(4' $\left.\varnothing 2^{\prime}\right)$ oligonucleotide System

(Gerhard Quinkert zum 75. Geburtstag gewidmet)

Helv. Chim. Acta, 2002, 85, 399

230. X. Wu, S. Guntha, M. Ferencic, R. Krishnamurthy, A. Eschenmoser

Base-Pairing Systems Related to TNA: $\alpha$-Threofuranosyl Oligonucleotides Containing Phosphoramidate Linkages

Org. Lett., 2002, 4, 1279

231. X. Wu, G. Delgado, R. Krishnamurthy, A. Eschenmoser

2,6-Diaminopurine in TNA: Effect on Duplex Stabilities and on the Efficiency of TemplateControlled Ligations

Org. Lett., 2002, 4, 1283

232. A. Eschenmoser

Die Lehre der Chemie an den Hochschulen

Chemie Report. at 2002, Heft 3, 38-39

233. C.J. Wilds, Z. Wawrzak, R. Krishnamurthy, A. Eschenmoser, M. Egli

Crystal Structure of a B-Form DNA Duplex Containing (L)- $\alpha$-Threofuranosyl (3' $\left.\varnothing 2^{\prime}\right)$ Nucleosides: A Four-Carbon Sugar is Easily Accommodated into the Backbone of DNA J. Am. Chem. Soc., 2002, 124, 13716 
234. A. Eschenmoser, U.-H. Felcht, R. Flöhl, M. Göbel, D. Hoelzer, G. Quinkert, H. Schwarz, G. Wess

Neuorientierung der Chemie - Mode oder mehr? (Podiumsdiskussion am 7.2. 2002 zum 75. Geburtstag von Prof. G. Quinkert, Universität Frankfurt/Main), G. Wess (Ed.), Aventis Pharma Deutschland GmbH, 2002, S. 1-35

235. M.-O. Ebert, A. Luther, H. K. Huynh, R. Krishnamurthy, A. Eschenmoser, B. Jaun

NMR Solution Structure of the Duplex Formed by Self-Pairing of $\alpha$-L-Arabinopyranosyl(4'Ø2')-(CGAATTCG)

(Dedicated to Prof. Dieter Seebach on the occasion of his 65th birthday)

Helv. Chim. Acta, 2002, 85, 4055

236. K-U. Schöning, P. Scholz, X. Wu, S. Guntha, G. Delgado, R. Krishnamurthy, A. Eschenmoser

The $\alpha$-L-Threofuranosyl-(3'-2')-oligonucleotide System ('TNA'): Synthesis and Pairing Properties

(Dieter Seebach zum 65. Geburtstag gewidmet)

Helv. Chim. Acta, 2002, 85, 4111

237. P. Wentworth Jr., J. E. McDunn, A. D. Wentworth, C. Takeuchi, J. Nieva, T. Jones, C. Bautista, J. M. Ruedi, A. Gutierrez, K. D. Janda, B. M. Babior, A. Eschenmoser, R. A. Lerner

Evidence for Antibody-Catalyzed Ozone Formation in Bacterial Killing and Inflammation Science, 2002, 298, 2195

238. P. Wentworth Jr., A. D. Wentworth, X. Zhu, I. A. Wilson, K. D. Janda, A. Eschenmoser, R. A. Lerner

Evidence for the production of trioxygen species during antibody-catalyzed chemical modification of antigens

Proc. Nat. Acad. Sci. USA, 2003, 100, 1490

239. Z. Wang, H. K. Huynh, B. Han, R. Krishnamurthy, A. Eschenmoser

2,6-Diamino-5,8-diaza-7,9-dicarba-purine

Org. Lett., 2003, 5, 2067

240. B. Han, Z. Wang, B. Jaun, R. Krishnamurthy, A. Eschenmoser

C-Nucleosidations with 2,6-Diamino-5,8-diaza-7,9-dicarbapurine

Org. Lett., 2003, 5, 2071

241. O. Jungmann, M. Beier, A. Luther, H. K. Huynh, M.-O. Ebert, B. Jaun, R. Krishnamurthy, A. Eschenmoser

Pentopyranosyl Oligonucleotide Systems. Comm. No. 13. The $\alpha$-L-Arabinopyranosyl(4'Ø2')-oligonucleotide System: Synthesis and Pairing Properties

Helv. Chim. Acta, 2003, 86, 1259

242. R. A. Lerner, A. Eschenmoser

Ozone in biology 
Proc. Nat. Acad. Sci. USA, 2003, 100, 3013

243. P. Wentworth Jr., J. Nieva, C. Takeuchi, R. Galve, A. D. Wentworth, R. B. Dilley, G. A. DeLaria, A. Saven, B. M. Babior, K.D. Janda, A. Eschenmoser, R. A. Lerner Evidence for Ozone Formation in Human Atherosclerotic Arteries Science, 2003, 302, 1053

244. S. Pitsch, S. Wendeborn, R. Krishnamurthy, A. Holzner, M. Minton, M. Bolli, C. Miculka, N. Windhab, R. Micura, M. Stanek, B. Jaun, A. Eschenmoser Pentopyranosyl Oligonucleotide Systems. 9th comm. The $\beta$-D-Ribopyranosyl-(4' $\varnothing 2$ ')oligonucleotide System ("Pyranosyl-RNA"): Synthesis and Resumé of Base-Pairing Properties

(Duilio Arigoni zu seinem 75. Geburtstag gewidmet, in Erinnerung an gute alte Zeiten) Helv. Chim. Acta, 2003, 86, 4270

245. P. S. Pallan, C. J. Wilds, Z. Wawrzak, R. Krishnamurthy, A. Eschenmoser, M. Egli Why Does TNA Cross-Pair More Strongly with RNA Than with DNA? An Answer From Xray Analysis

Angew. Chem., 2003, 115, 6073

Angew. Chem. Int. Ed., 2003, 42, 5893

246. A. Eschenmoser

A Sentimental Journey: From the Biogenetic Isoprene Rule to the Chemical Etiology of Nucleic Acid Structure

38th National Organic Symposium, Indiana University, Bloomington/IN, USA (Abstract for Roger Adams Award Lecture, June 8-12, 2003) pp. 22-23

247. A. Eschenmoser

The TNA-Family of Nucleic Acid Systems: Properties and Prospects

Origins Life Evol. Biosphere, 2004, 34, 277

248. X. Zhu, P. Wentworth, Jr., A. D. Wentworth, A. Eschenmoser, R. A. Lerner, I. A. Wilson Probing the antibody-catalyzed water-oxidation pathway at atomic resolution

Proc. Nat. Acad. Sci. USA, 2004, 101, 2247

249. Q. Zhang, E. T. Powers, J. Nieva, M. E. Huff, M.A. Dendle, J. Bieschke, C. G. Glabe, A. Eschenmoser, P. Wentworth, Jr., R. A. Lerner, J. W. Kelly

Metabolite-initiated protein misfolding may trigger Alzheimer's disease

Proc. Nat. Acad. Sci. USA, 2004, 101, 4752

250. N. Hall (in part), A. Eschenmoser

The quest for the chemical roots of life (Focus Article)

J. Chem. Soc., Chem. Commun., 2004, 1247

251. M. Ferencic, G. Reddy, X. Wu, S. Guntha, J. Nandy, R. Krishnamurthy, A. Eschenmoser Base-Pairing Systems Related to TNA Containing Phosphoramidate Linkages: Synthesis of Building Blocks and Pairing Properties 
Chem. Biodiv., 2004, 1, 939

252. P. T. Nyffeler, N. A. Boyle, L. Eltepu, C.-H. Wong, A. Eschenmoser, R. A. Lerner, P. Wentworth, Jr.

Dihydrogen Trioxide $(\mathrm{HOOOH})$ Is Generated during the Thermal Reaction between Hydrogen Peroxide and Ozone (In memory of Bernard (Bernie) M. Babior)

Angew. Chem., 2004, 116, 4756

Angew. Chem. Int. Ed., 2004, 43, 4656

253. B. Han, B. Jaun, R. Krishnamurthy, A. Eschenmoser

Mannich-Type C-Nucleosidations in the 5,8-Diaza-7,9-dicarbapurine Family

Org. Lett., 2004, 6, 3691

254. B. Han, V. Rajwanshi, J. Nandy, R. Krishnamurthy, A. Eschenmoser

Mannich-Type C-Nucleosidations with 7-Carba-purines and 4-Aminopyrimidines

Synlett, 2005, No. 5, 744

255. T. Wagner, B. Han, G. Koch, R. Krishnamurthy, A. Eschenmoser

Tautomerism in 5,8-Diaza-7,9-dicarbaguanine ("Alloguanine")

Helv. Chim. Acta, 2005, 88, 1960

256. A. Eschenmoser

Searching for Nucleic Acid Alternatives

Chimia, 2005, 59, 836

257. A. Eschenmoser, D. Arigoni

Revisited after 50 Years: The 'Stereochemical Interpretation of the Biogenetic Isoprene Rule for the Triterpenes'

(In memoriam Leopold Ruzicka and Oskar Jeger)

Helv. Chim. Acta, 2005, 88, 3011

(mit der englischen Übersetzung der 1955 in deutscher Sprache erschienenen Arbeit: A. Eschenmoser, L. Ruzicka, O. Jeger, D. Arigoni, Helv. Chim. Acta, 1955, 38, 1890, 'Zur Kenntnis der Triterpene. 190. Mitteilung. Eine stereochemische Interpretation der biogenetischen Isoprenregel bei den Triterpenen')

258. M. Egli, P. S. Pallan, R. Pattanayek, C. J. Wilds, P. Lubini, G. Minasov, M. Dobler, C. J. Leumann, A. Eschenmoser

Crystal Structure of Homo-DNA and Nature's Choice of Pentose over Hexose in the Genetic System

J. Am. Chem. Soc., 2006, 128, 10847

259. D. Arigoni, J. D. Dunitz, A. Eschenmoser

Vladimir Prelog, 23 July 1906 - 7 January 1998

(On the occasion of his 100th birthday)

(s. auch: Biog. Mems. Fell. R. Soc. Lond. 46, 443-464 (2000))

Helv. Chim. Acta, 2006, 89, 1267 
260. G. K. Mittapalli, K. R. Reddy, H. Xiong, O. Munoz, B. Han, F. De Riccardis, R. Krishnamurthy, A. Eschenmoser

Mapping the Landscape of Potentially Primordial Informational Oligomers: Oligodipeptides and Oligodipeptoids Tagged with Triazines as Recognition Elements

Angew. Chem., 2007, 119, 2522

Angew. Chem. Int. Ed., 2007, 46, 2470

261. G. K. Mittapalli, Y. M. Osornio, M. A. Guerrero, K. R. Reddy, R. Krishnamurthy, A. Eschenmoser

Mapping the Landscape of Potentially Primordial Informational Oligomers: Oligodipeptides Tagged with 2,4-Disubstituted 5-Aminopyrimidines as Recognition Elements

Angew. Chem., 2007, 119, 2530

Angew. Chem. Int. Ed., 2007, 46, 2478

262. D. Seebach, A. K. Beck, D. M. Badine, M. Limbach, A. Eschenmoser, A. M. Treasurywala, R. Hobi, W. Prikoszovich, B. Linder

Are Oxazolidinones Really Unproductive, Parasitic Species in Proline Catalysis? Thoughts and Experiments Pointing to an Alternative View

(Dedicated to Prof. Yoshito Kishi on the occasion of his $70^{\text {th }}$ birthday)

Helv. Chim. Acta, 2007, 90, 425

263. K. Koch, B. Schweizer, A. Eschenmoser

Reactions of the HCN-Tetramer with Aldehydes (for Leslie E. Orgel, the radical empiricist) Chemistry and Biodiversity, 2007, 4, 541

264. A. Eschenmoser

On a Hypothetical Generational Relationship between $\mathrm{HCN}$ and Constituents of the Reductive Citric Acid Cycle (for Leslie E. Orgel, the critical conceptualist)

Chemistry and Biodiversity, 2007, 4, 554

265. A. Eschenmoser

Question 1: Commentary Referring to the Statement "The Origin of Life can be Traced Back to the Origin of Kinetic Control" and the Question "Do You Agree with this Statement; and How Would You Envisage the Prebiotic Evolutionary Bridge Between Thermodynamic and Kinetic Control?" (Stated in Section 1.1.)

Orig. Life Evol. Biosph., 2007, 37, 309

266. A. Eschenmoser

The search for the chemistry of life's origin

Tetrahedron, 2007, 63, 12821

267. A. Eschenmoser

Creating a perspective for comparing in: J. D. Barrow et al. (Eds.), 'Fitness of the Cosmos for Life: Biochemistry and Fine-Tuning' (workshop Templeton Found., Harvard University, Oct. 2003), Cambridge Univ. Press, Cambridge, 2007, Part IV, chapter 16, pp. 349 - 365 
Prelog Medal 2007

Laudatio for Scott Denmark

Chimia, 2008, 62, 35

269. M.-O. Ebert, C. Mang, R. Krishnamurthy, A. Eschenmoser, B. Jaun

The Structure of a TNA-TNA Complex in Solution: NMR Study of the Octamer Duplex Derived from $\alpha$-(L)-Threofuranosyl-(3' - 2')-CGAATTCG

J. Am. Chem. Soc., 2008, 130, 15105

270. A. Eschenmoser

The Search for the Chemistry of Life's Origin

(Proceed. of the Plenary Session on 'Scientific Insights into the Evolution of the Universe and of Life')

Pontif. Acad. Sci. Acta., 2009, 20, 181

271. A. Eschenmoser

Darwin's 'Warm Little Pond', Orden Pour le mérite für Wissenschaften und Künste, Reden und Gedenkworte, Wallstein Verlag, 2008-2009, Bd. 37. 